\title{
Usage of spatial lattice metal structures as roofing for mechanical equipment rooms of hydroelectric power stations
}

\author{
Mikhail Balzannikov ${ }^{1}$, Vadim Alpatov ${ }^{1,}{ }^{*}$, Igor Kholopov ${ }^{1}$, Andrey Saharov ${ }^{1}$ and Aleksey \\ Lukin $^{1}$ \\ ${ }^{1}$ Samara State University of Architecture and Civil Engineering, Molodogvardeiskaia str. 194, \\ 443001, Samara, Russia
}

\begin{abstract}
The paper focuses on technical analysis of spatial attice structures used in roofing of mechanical equipment rooms of hydroelectric power stations in Russia. The analysis reveals that spatial structures of "Markhi" type are used most frequently there and shows their advantages and disadvantages. The authors put forward their own solution for combining advantages of spatial spatial lattice roofing structures with those of truss frames with gusset plate units. The solution is aimed at enhancing the safety and reliability of hydraulic engineering constructions with no changes in accuracy requirements to their manufacturing. The authors also introduce their model of a spatial lattice roofing unit and give an account of its reliability and strength based on software system calculations.
\end{abstract}

\section{Introduction}

Hydroelectric power stations are considered to be hydro-engineering constructions of high level of hazard (1st Degree Amenability according to the classification accepted in Russia). Usually these constructions are unique. The safety and reliability demands for designing, building and operating hydroelectric power stations are very high. One of the most important parts of any hydroelectric power station is a mechanical equipment room. A typical mechanical equipment room is usually of a considerable length with more than 24meters bays. Spatial lattice roofing structures (as Fig. 1 shows) are used very frequently in mechanical equipment rooms. Metal spatial lattice roofing structures of "Structure" type have been successfully used in mechanical equipment rooms of hydroelectric power stations. They have also been proved effective.

Corresponding author: avu75@mail.ru 


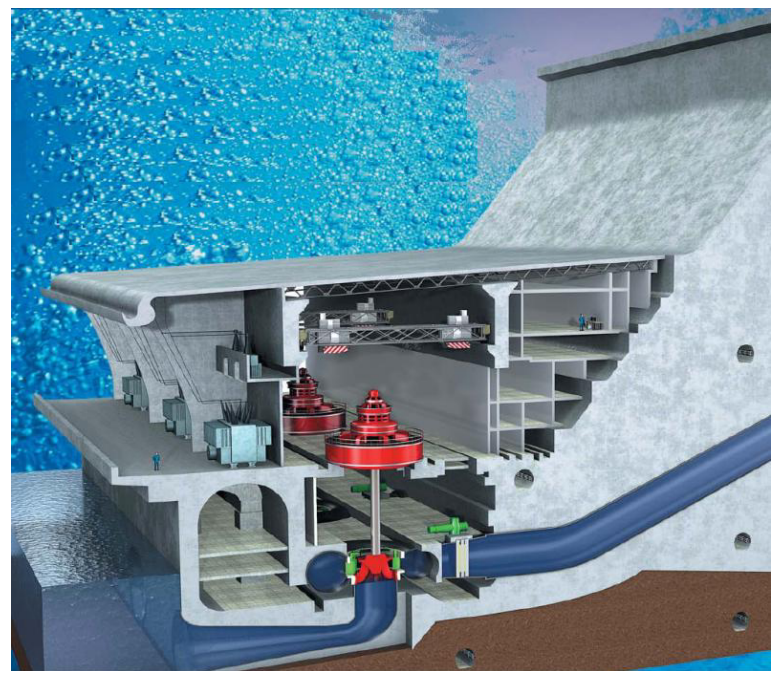

Fig. 1. Spatial spatial lattice roofing structure of a mechanical equipment room, a hydroelectric power station (ANSYS Advantage №15’2011, cover image)

"Structure" has a lot of competitive advantages over other alternative roofing structures. The most important advantages of "Structure" are comparatively little material consumption, the possibility of check assembly in advance and of packaged supply, a block building system, route sequence of mechanical processing, availability of many different parts of one and the same type. "Structure" has no balks, beams and connections typical for other metallic constructions. "Structure" is also characterized by advanced rigidness. The proportion of height to bay in these constructions is about $1 / 16-1 / 25$. High reliability of "Structure" is based on its multi-indeterminateness. This high reliability (sometimes referred to as "survivability") is mostly due to spatial work of its mechanical system, and also to numerous redundant restraints which give the construction the ability to redistribute forces. "Structure" is a Spatial geometrically invariable structure. Spatial work of "Structure" is evident under non-uniform loads. In such a case overburden pressure on most auxiliary bars (excluding those bars without which the system becomes a kind of a mechanism) does not generally interfere with the normal work of the construction because of its ability to redistribute forces. As far as structural slabs are characterized with advanced rigidness and are of low weight it is reasonable to use them as long span structures. Structural roofing installation can be done as follows: by balanced erection, by erection on design level of trestlework, by erection of the whole construction or its large parts on the ground, by erection of its enlarged blocks. Almost all these types of erection have been tested on different construction sites [1]. Important stage of economic design of large-span metal rod systems is application of methods of optimization [2-6].

\section{The model of a spatial lattice roofing unit}

Comparative analysis of metal structures used in roofing of mechanical equipment rooms of hydroelectric power stations in Russia showed that only two types of such constructions are usually used. It's either traditional constructions (they are two dimensional trussed rafters of various forms and with different lattice design) or spatial structures of "Markhi" type. "Markhi" was introduced in 1969 by the Department of Engineering Construction of Moscow Architectural Institute. "Markhi" present the next stage in the development of famous German MERO structures (Fig. 2). 
The effective service of cross bar constructions depends mostly on the type of joint connection as they contain from 8 to 18 bars connected at different angles. In the most simple structures (which consist of lattice girders intercrossing in one and the same vertical subspace) this connection is usually used to reduce the height of the construction in one level. The girders are interconnected in such unit with the help of cross joint plate, the components of the boom are split in the unit and the joint is covered with a similar gusset sheet joint plate.

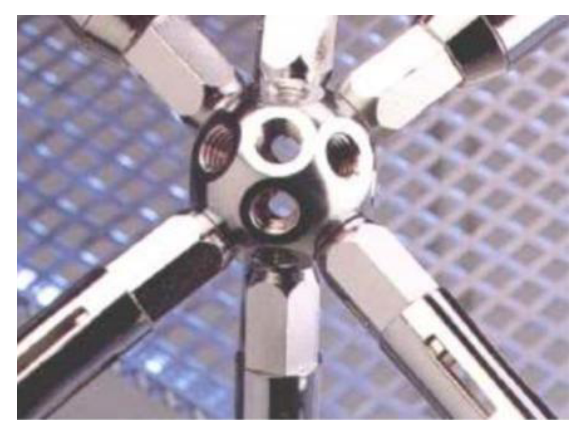

Fig. 2. A unit of MERO system

Both "Markhi" and MERO structures require special unit connectors to be made in the form either of a sphere or of a polyhedral with specially cut tap holes. They also impose strict accuracy requirements to their manufacturing and assembling. Traditional trussed metal rafters have units which are usually made on sheet joint plates and they are able to compensate deviations. The authors here suggest combining positive characteristics of spatial structures and those of trussed rafters on sheet joint plates to design a spatial lattice structure with units on sheet joint plates [7]. Such a structure would combine advantages of spatial structures with the ability to compensate deviations. The authors believe it can be successfully used while roofing building of different types including mechanical equipment rooms of hydroelectric power stations (in designing, building and reconstructing those rooms).

It is believed that separate parts of structural constructions are exposed only to tensile force and direct stress. The situation with unit connectors of these constructions is different. A unit connector in such a construction combines various bars and consequently is under a constant state of tension. Unit connectors of structural constructions should definitely be characterized by enhanced reliability as in case of only one connector failure the whole group of bar fails. That why special attention should be given to these unit connectors and their elements while designing and manufacturing them. To assure it the authors carried out a numerical experiment through simulating the suggested unit connector's stress state. The unit connector is shown below (Figure 3). It is made of sheet joint plates. According to existing recommendations the bulk of the gusset plate should depend on the pressure of the element attached to it (Y.M. Likhtarnikov, Raschet stalnyh constustsiy, Kiev, 1984). However, these recommendations are aimed at flat girder constructions with twin angle joints. There are no recommendations for spatial constructions yet. The authors believe that the stress level of the gusset plate will be reduced and, consequently, the bulk of the gusset plate can be narrowed. The authors of the paper made it their aim to trace the stress pattern in a gusset plate of a spatial construction, to quantify the stress levels in it and to estimate a possibility to make the bulk of the gusset plate narrower than the recommended bulk of a flat girder. The authors have succeeded in doing it by numerical simulation with the help of the modern automated design system (CAD/CAM/CAE).

To determine the rated force applied to a unit connector the authors analyzed design and engineering developments of different spatial constructions for various patterns of loading. 
Analyzing the most unfavorable combinations of strain and stress factors which affect the parts of spatial constructions connected with different elements the authors found the most stress-suffering units and calculated their stress-strain state (SSS). Modern software systems of mechanical systems structural analysis - the systems based on finite-element method - were used to analyze SSS of the units in question. All four software systems were used in this analysis to eliminate mistakes in making the simulation model, to eliminate all possible mistakes in the work of those systems, and to verify accuracy of the research.

This paper presents the results of the numerical study of one the units belonging to a lower level. This unit connects eight bars. The loading stress was calculated for these bars. The strain stress in them was simulated with the help of numerical study of bar models of spatial constructions exposed to outer loadings. The scheme of this unit loading is shown on Fig. 4.

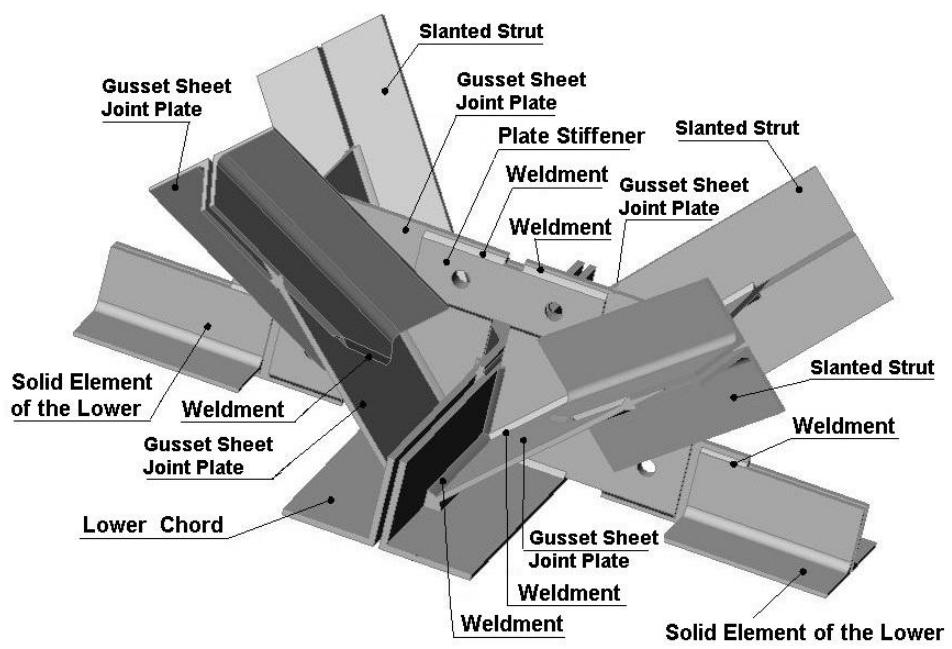

Fig. 3. A unit of spatial bar construction on gusset sheet joint plate

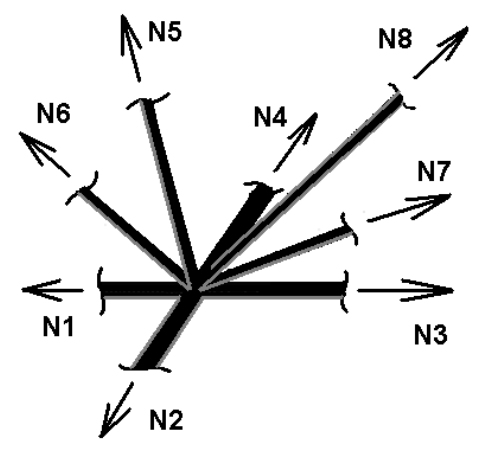

Fig. 4. The scheme of this unit outer loadings

Computational engineering and software of today are capable of calculating almost any of the most advanced systems.

The modern automated design system (CAD/CAE) helps researchers and designers choose appropriate methods and tools [8]. The authors of the paper can mention the following CAD/CAE systems: CosmosM, CosmosWorks, DesignSpace, Ansys, Abaqus, Nastran, Staad, Sap, "Lira”, "MIRAZH”, SCAD, Ansys. 
The units of the structural construction in question were investigated with the help of CosmosWorks, DesignSpace, "Lira", SCAD. Figure 5 show the results of investigation carried out with "Lira".

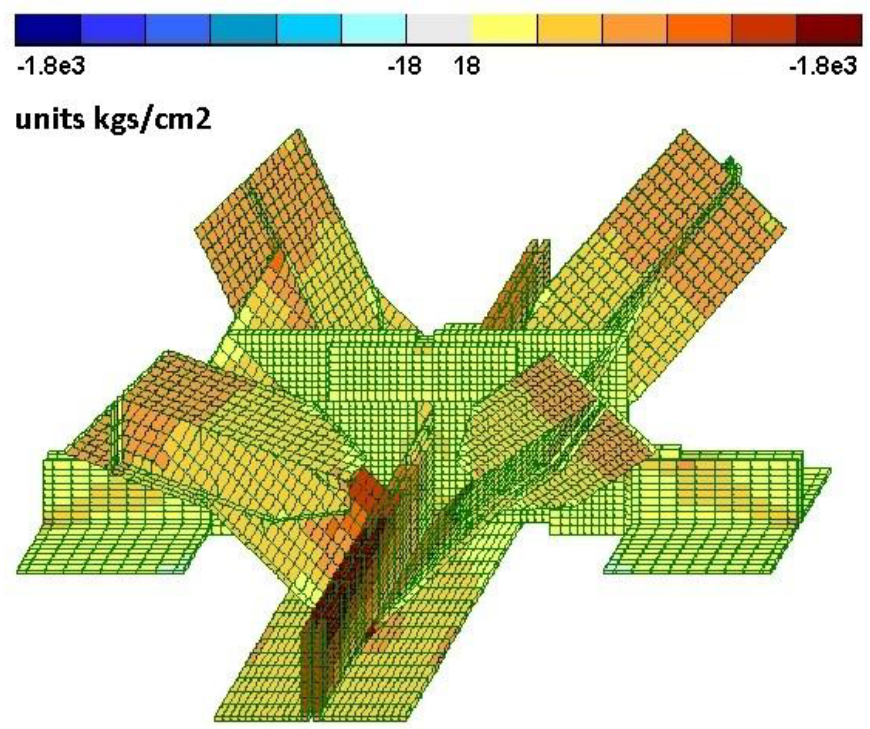

Fig. 5. Stress strain of the unit calculated with "Lira"

Figure 5 shows a calculation model of the unit in question. Finite elements of the calculation model are shown as six- and eight-units spatial finite elements of some form or other. The calculation model contains 14435 units and 7733 elements. The characteristics of the material these elements are made of correspond to Steel grade C245 ( $\mathrm{Ry}=240 \mathrm{M \Pi a}$, $\mathrm{E}=2 \cdot 1011 \mathrm{H} / \mathrm{M} 2, \mathrm{c}=0.3$ ).

Figure 6 demonstrates the results of the investigation. It illustrates stress distribution in the calculation model. The figure clearly shows that gusset plates are used in the so-called region of material elastic work and are $26.6 \%$ under loaded. According to the research the other units of the construction have equal excess strength. It leads us to the conclusion that if we follow the recommendations for the bulk of the gusset plates in designing spatial structures it might lead to the excess of the materials used. Stress strain calculations of the same unit with other systems vary from $12 \%$ (Cosmos) to $26.6 \%$ ("Lira").

\section{Conclusions}

1. First-hand experience shows that spatial structural constructions, being structures of high "survivability", enhance reliability of potentially hazardous buildings and constructions when they are used as roofing.

2. The authors of the paper introduce the unit connector of a spatial lattice metal construction which makes possible to reduce strict accuracy requirements to its manufacturing with no loss of its reliability or safety.

3. Analysis of the calculation model of the unit showed that the bulk of the gusset plate can be narrowed in comparison with the required bulk of a gusset plate in a flat girder. 


\section{References}

1. Building and Propety, Internet Journal, №35, (2005), http://www.nestor.minsk.by/sn/

2. Chang-Yu Cui, Bao-Shi Jiang, Engineering Structures, 77, 109-118 (2014)

3. Lazaros Elias Mavromatidis, Energy and Buildings, 106, 192-202 (2015)

4. M. I. Balzannikov, I. S. Kholopov, V. Yu. Alpatov, A. A. Lukin, Procedia Engineering, 111, 72-81 (2015)

5. V. Yu. Alpatov, A. A. Lukin, Procedia Engineering, 111, 20-29 (2015)

6. V. Yu. Alpatov, Procedia Engineering, 91, 177-182 (2014),

7. V.Yu. Alpatov, I.S. Kholopov, Sterzhnevaya strukturnaya konstruktsia iz dlinnorazmernykh elementov (Frame Structure made of long dimensional elements), RU Patent 33381. (2003)

8. Y. Gorokhov, V. Mushchanov, I. Romenskii, A. Muschanov, Metal constructions, 21(4), 191-206 (2015) 